\title{
DAMPING IN BUILDING STRUCTURES BY MEANS OF PTFE SLIDING JOINTS
}

\author{
R. G. Tyler*
}

\section{ABSTRACT}

The characteristics of PTFE sliding joints when used to separate secondary components from the main structure of a building are described. Their use enables damping of earthquake and wind motions to be obtained within the normal elastic range of the structure, and beyond, by virtue of the frictional forces generated, while temperature movements are at the same time accommodated. In addition a positive fixing is obtained which is a useful alternative to the hung-type of fixing which is at present recommended where separation is required.

Further testing is needed to obtain more friction data on filled PTFE materials and suitable joints need to be developed.

\section{INTRODUCTION}

Up to the recent past lack of clear understanding of the rule of stiff panels within buildings during earthquakes led to their haphazard introduction after the structural design was complete, to the detriment of structural action. One of the most common instances of failure has been that of ground floor columns, when partitions of indeterminate yet considerable stiffness, have been introduced above ground floor level, while the ground floor has been left in open plan for car parking or a shopping complex.(1)

From the reserve energy point of view the indiscriminate introduction of rigid panels inevitably promotes early failure since the stored energy capacity is reduced at points where unwanted rigidities are introduced. It has to be remembered that the amount of stored energy is proportional to the square of the stress. Thus a maximum number of points should be rising to yield simultaneously. Failing to achieve this results in a more severe attack on the few remaining highly stressed points, such as the ground floor columns in the example quoted above. An analogy is found in the classic text-book example of the bolt of uniform strength, when the shank of the bolt is turned down to the diameter at the thread bottom in order to provide maximum stretch, and hence shock absorbing capacity, in the bolt.

Quite apart from the risk to the integrity of the structure the arbitrary connection of secondary elements to the main structural frame can cause extensive damage to the decor and services within the building during an earthquake, rendering the building unserviceable for a long time afterwards. In consequence it has now become accepted that non-structural elements should be separated from the structural frame, a subject which has been comprehensively covered by Glogau(3) and Blakeley (4). This does, however, present some difficulties in that in-plane freedom

\footnotetext{
* Physics and Engineering Laboratory, Department of Scientific and Industrial Research, Lower Hutt.
}

of movement must be allowed around three sides of a panel or partition, which results in the need to hang or guide the upper part if fixing is carried out at the base. In addition there is a disadvantage in that damping of the structure is reduced.

In this paper it is shown that an intermediate course is possible. If PTFE sliding elements are introduced at the joints then a positive fixing will be provided around secondary elements, which can be loaded within their capacity when the joints slip within a known force range. In this way it is possible to provide damping, and at the same time, make a reasoned allowance for the effect of secondary elements in the design of the main structure.

\section{DYNAMIC CHARACTERISTICS OF THE PTFE SLIDING JOINTS}

Tests have already been carried out at the New Zealand Department of Scientific and Industrial Research Physics and Engineering Laboratory on the characteristics of
stainless steel sliding on pure PTFE At high velocities the friction force peaks on the first cycle of loading and then decays during the following cycles. A near rectangular hysteresis loop is obtained indicating a good energy absorption characteristic. The frictional coefficient goes down as the bearing pressure goes up, with the result that the product of these two quantities, i.e. the frictional force in the bearing, has a comparatively flat characteristic. Results from the tests, taken from Table $2(5)$, are shown plotted in Fig. 1. Taking the temperature inside a building as $20^{\circ} \mathrm{C}$, the frictional force per unit area of joint is given by the hatched area for the first five cycles of loading, when the peak velocity is $38 \mathrm{~cm} / \mathrm{sec}$ and the peak acceleration is $0.2 \mathrm{~g}$ for each stroke of $\pm 75 \mathrm{~mm}$. Thus, for these conditions, a panel would need to be designed for a joint force corresponding to the peak on the upper curve, i.e. about

\# PTFE or polytetrafluoroethylene, which is known under the trade name Teflon, is described as a fluorocarbon resin. 
2.8 $\mathrm{MN} / \mathrm{m}^{2}$, while the expected damping during the earthquake could be taken from the curve after 5 cycles, and would be in the range 1.0 to $1.4 \mathrm{MN} / \mathrm{m}^{2}$, i.e. a surprisingly flat characteristic. Thus bolt tightening need not be carried out to within fine limits to obtain a controlled measure of structural damping. Nor would friction be reduced appreciably at speeds down to one quarter of those quoted above (5). The tests also showed that PTFE joints are remarkably silent in operation. Thus much of the noise caused by the fracturing and degradation of interior panels within a building would be avoided by their use with appropriate clearances around members, while in addition the amount of sway in the building would be reduced, both in earthquakes and windstorms. During earthquakes the ductility demands on the frame would be substantially reduced.

\section{DESIGN LOADS ON PANELS}

For joints located at panel tops in the manner outlined by Glogau, the arrangement could be as shown in Fig. 2, with some provision for the deformation of the supporting beam. Distortion of the rectangular frame of the building would generate shear forces at the joints and tensions and compressions within the panel as shown, with directions reversing as distortion occurs in the opposite direction. Each partition in a building can be used to generate damping according to its own stiffness and strength. Thus a reinforced concrete panel could be used to generate a large amount of damping and a lightweight timber one very little, with blockwork as an intermediate. If a large number of PTFE joints are envisaged then there is an analogy with the old rivetted type of structure which was well known for its capacity to resist dynamic loads by virtue of its ability to slip at the joints. In the case of the PTFE joint, however, there is an advantage in that much larger slippage can occur and the slipping load can be controlled to any desired value.

As an example of a typical diagonal loading of a panel, if an M24 (24 mm) high tensile bolt is used with two PTFE sliding surfaces, one on each side of a symmetrical joint (See Fig 4) then:

Induced bolt preload ) at $65 \%$ of proof load

\section{$=131 \mathrm{kN}$}

Total area of PTFE surfaces required at a target tightening pressure of say 25 $\mathrm{MN} / \mathrm{m}^{2}$ $=0.131 / 25 \mathrm{~m}^{2}=52.5 \mathrm{~cm}^{2}$

Maximum frictional force generated during first cycle of loading

$=2.80 \times$ joint area

$=2.80 \times 0.00525 \mathrm{MN}$

$=14.7 \mathrm{kN}$ at $45^{\circ}$ to the vertical.

The corresponding horizontal shear would be $14.7 / \sqrt{2} \mathrm{kN}$.

The total horizontal force generated will be the sum of the forces at all similar joints at the same level i.e. $30 \mathrm{kN}$ for the panel shown in Fig. 2. After 5 cycles the damping force will have dropped to about one third of this value, i.e, about $10 \mathrm{kN}$

\section{TYPES OF JOINT}

In Canada, a PTFE joint has already been used for curtain walls in a building to allow temperature movements to occur( 6 ) (Fig. 3). In this joint, PTFE sliding on PTFE is employed, and joints are provided at alternate floor levels of a 56 storey tower block.

This type of joint could be used to absorb earthquake movements but may suffer from the eccentricity of loading of the bolt under dynamic conditions. A symmetrical arrangement such as that detailed in Fig. 4 would be preferable for partitions, with a maximum length of bolt under tension to preserve the load on the PTFE as this wears over the years. Initially, before tightening the bolts, the parts would need to be manufactured or shimmed to be a close fit, so that the clamping induced by the bolt action causes a positive grip on the PTFE. The clearance around the bolt would need to be sufficient to allow for the expected frame distortion, which may be up to $50 \mathrm{~mm}$ in typical applications (3).

In such a joint filled PTFE sliding on filled PTFE would probably be employed. The use of filled PTFE would enable higher pressures to be utilized. Research will shortly be carried out on such elements in the dynamic friction rig at the physics and Engineering Laboratory. It is hoped to assess glass and bronze filled PTFE initially, but present indications from the literature suggest that dynamic friction may not vary greatly from the pure PTFE on stainless steel application which was the subject of recent tests. Data for one such material, Glacier DU (7) which is a filled bronze, is given in Fig. 5, taken from the manufacturer's literature. It is seen that, while there is a gap in the data at the faster speeds and higher pressures, which would be applicable to earthquake conditions, presumably because of a shorter life which makes such conditions unsuitable for mechanical applications, the likely trend is for coefficients of fxiction of the same order of magnitude as those found in the recent tests at the Laboratory. General requirements for PTFE filled bearings are given in a proposed American Standard (8), and further details of general properties in the Dupont literature $(6)$

\section{COMMENT}

PTFE joints should be considered for use in the fixing of external cladding to buildings. Not only would the joints allow temperature movements to take place, but damping could be derived from the whole of the cladding on a building. For internal partitions the joints would best be used in an orderly arrangement of panels, such as a torsion box, from top to bottom of the building, so that shears generated at one level are not thrown back on to the main structure at a lower level, where no panelling exists. If they are, then the forces will need to be allowed for.

The advantages of employing PTFE joints are seen as follows :- 
1. A positive fixing is obtained although in-plane movement is possible.

2. Damping of building movements arising from both wind and earthquake is obtained within the elastic range of the structure and beyond. The greater the velocity the greater the damping force.

3. Temperature movement will be accommodated. The advantage of PTFE over other materials which could be used in a friction damper is that where a structure has to undergo a large number of comparatively slow temperature movements during its life, as in the case of a bridge, then these will occur at quite low coefficients of friction, usually of the order of 3 o, with little fatigue of the structure, always provided the joints remain clean.

4. Non-structural elements within a building can be made to contribute to damping according to their own strength capacity.

5. Movement will occur silently, provided clearances are maintained around secondary elements.

Since the effects of floors can be to seriously modify structural action by reducing stress levels in beams, with a consequent increase in the ductility demand on columns, consideration should be given to isolating floors from the main structure by using PTFE bearing pads, when again energy absorption would be obtained.

\section{CONCLUSION}

The use of PTFE sliding elements within buildings to connect secondary elements to the main structure offers the advantage that any desired degree of damping can be provided within the strength of the secondary elements, which can be chosen accordingly. This could be of particular advantage to a steel structure where only $2 \%$ of damping may be inherent in the framework itself.
Further testing is needed to obtain more data on friction for filled PTFE layers, while a programme of joint development for particular applications is required.

\section{REFERENCES}

1. Skinner, R. I., Omote, S., Osawa, Y. and Yoshimi, Y. Philippines Luzon Earthquake of 2 August 1968. Unesco Serial No. 977/BMS. RD/SCE. NR. Paris, January, 1969.

2. Blume, J. A. Newmark, N. M. Corning, I. H., Design of Multistorey Reinforced Concrete Buildings for Earthquake Motions. Portland Cement Association, Illinois, 1961.

3. Glogau, O. A., Separation of NonStructural Components in Buildings. Bull. N.Z. Nat. Soc. Earthq. Eng.9 No. 3, Wellington, September, 1976.

4. Blakeley, R. W. G., A Review of the Code Provisions for Separation of Elements and Buildings. Bull. N.Z. Nat. Soc. Earthq. Eng. 7 No. 3. September 1974.

5. Tyler, R. G., Dynamic Tests on PTFE Sliding Layers Under Earthquake Conditions. Bull. N.Z. Nat. Soc. Eartha. Eng. (to be published).

6. Dupont, E.I. de Nemours \& Co. (Inc) Suggested Specifications for Filled Teflon TFE Resins used in Bearing Pads, Delaware, U.S.A.

7. The Glacier Metal Company Lta. DU Dry Bearings, Designer's Handbook No. 2, Nembley, England, 1973.

8. The Society of the Plastic Industry Inc., Fluorocarbons Division. Proposed standard for TFE Structural Bearing Surfaces (FD-117), Park Avenue, N.Y.

Paper received 9 September, 1977.

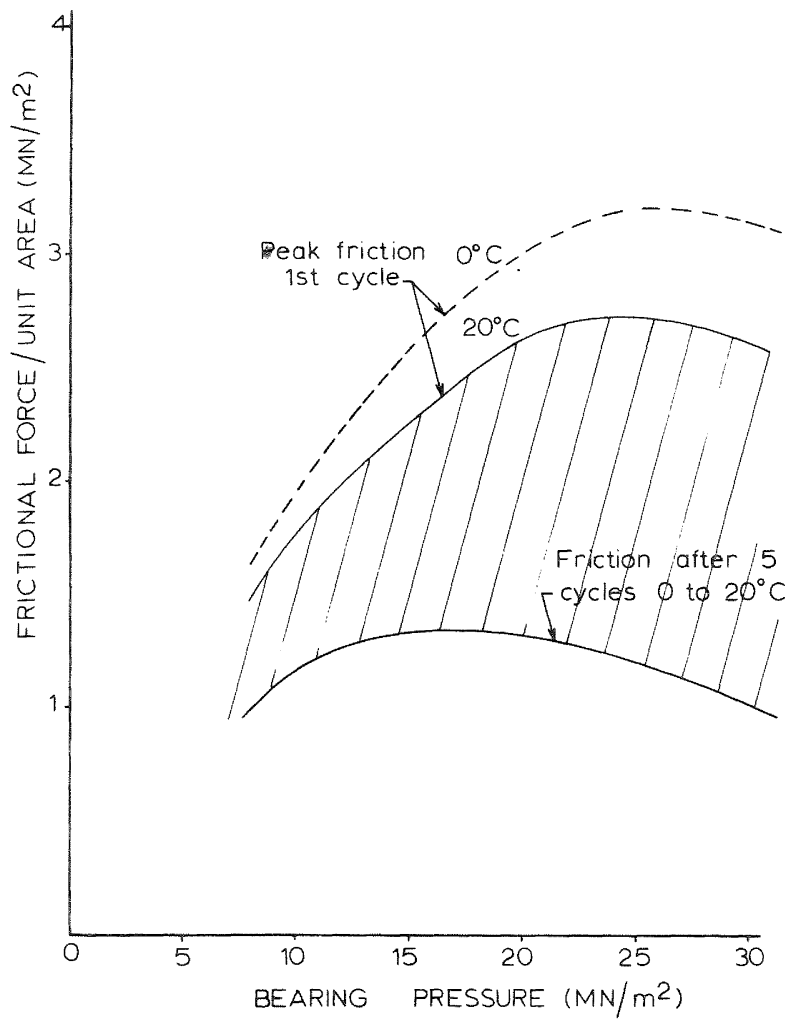




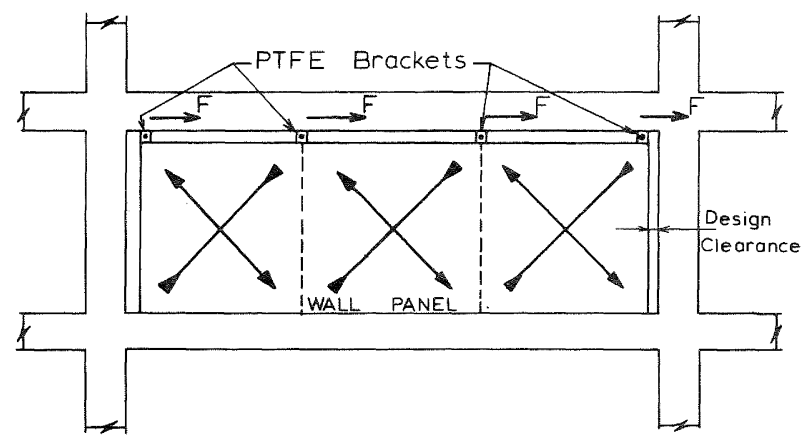

FIGURE 2: USE OF PTFE BRACKETS IN STRUCTURAL FRAME

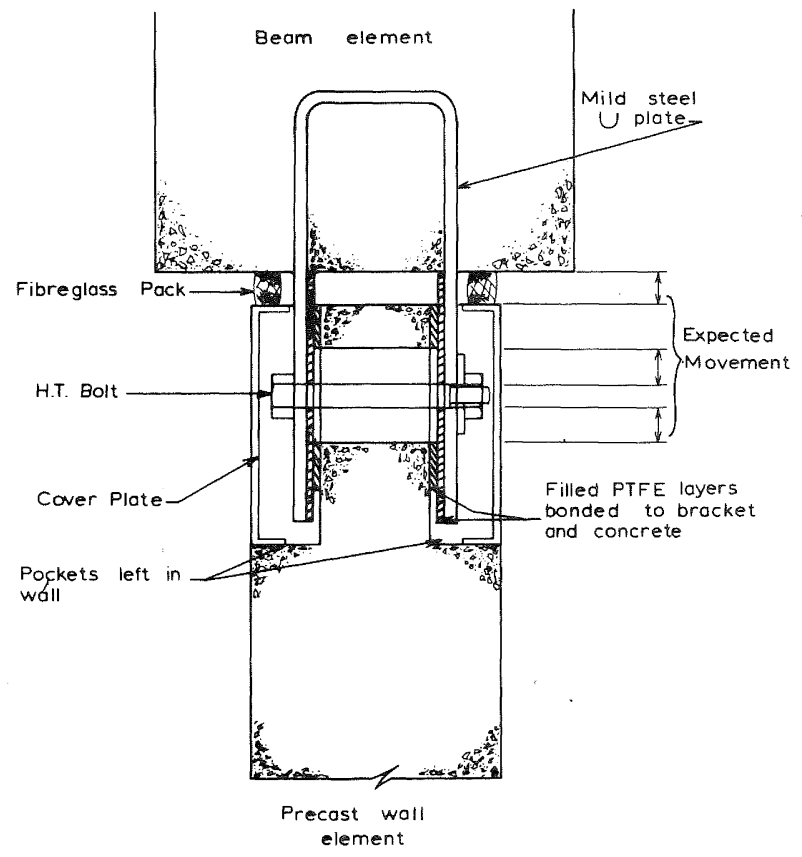

FIGURE 4: SUGGESTED PTFE MOVEMENT BRACKET FOR WALL ELEMENT

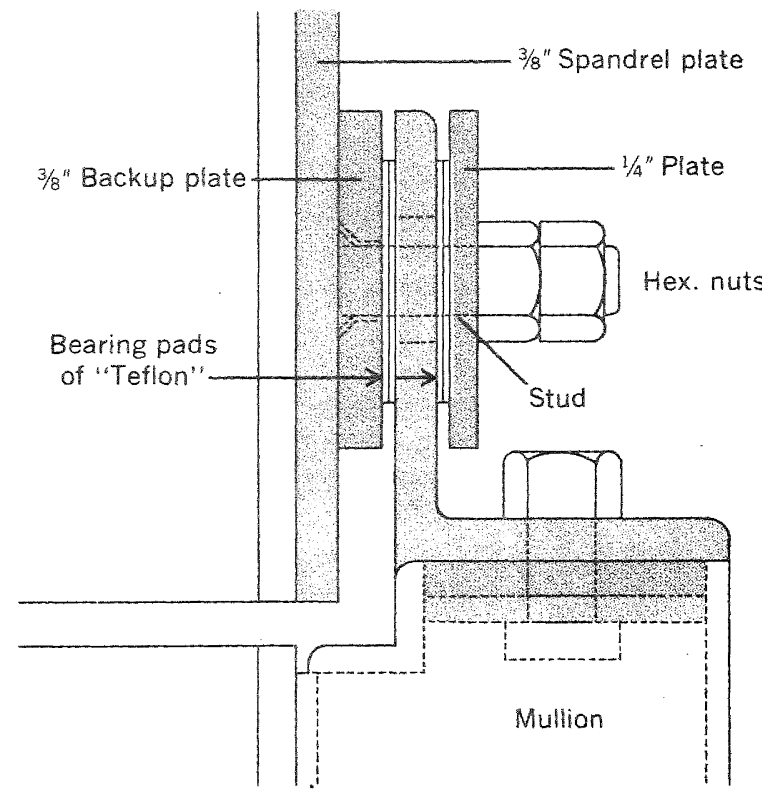

FIGURE 3: JOINT FOR CURTAIN WALLING (FROM DUPONT)

SLIDING SPEED $\mathrm{ft} / \mathrm{min}$

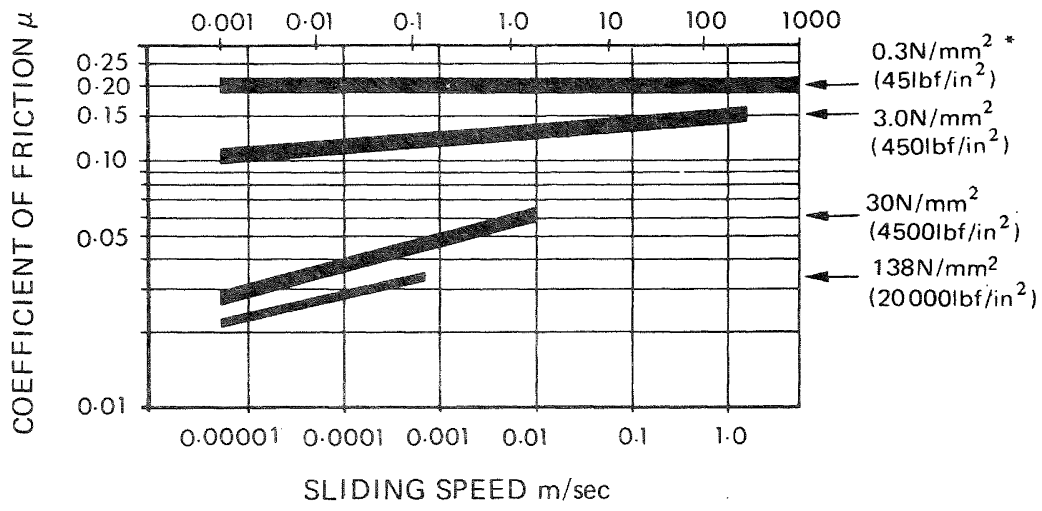

FIGURE 5: FRICTION DATA FOR GLACIER DU. (FROM GLACIER) 